\title{
Nicotine Ameliorates Emotional and Cognitive Impairments Induced by Neonatal PolyI:C Treatment in Mice
}

\author{
Jinghua $\mathrm{Yu}^{1,2,3, \dagger}$, Taku Nagai ${ }^{1,3, \dagger}$, Daisuke Ibi ${ }^{1}$, Yuko Kitahara ${ }^{1}$, Toshitaka Nabeshima ${ }^{2,3}$ and \\ Kiyofumi Yamada ${ }^{*}, 1,3,4$
}

${ }^{1}$ Department of Neuropsychopharmacology and Hospital Pharmacy, Nagoya University Graduate School of Medicine,
Nagoya, 466-8560, Japan
${ }^{2}$ Department of Chemical Pharmacology, Meijo University Graduate School of Pharmaceutical Sciences, Nagoya, 468-
8503, Japan

${ }^{3}$ The Academic Frontier Project for Private Universities, Comparative Cognitive Science Institutes, Meijo University, Nagoya 468-8502, Japan

${ }^{4}$ CREST, JST, 466-8560, Japan

\begin{abstract}
Environmental factors such as maternal and neonatal infection are potentially associated with the pathogenesis of various psychiatric disorders, including schizophrenia. Polyriboinosinic-polyribocytidilic acid (polyI:C) is a synthetic analogue of double-stranded RNA that induces strong innate immune responses. We have recently developed the mouse model of neurodevelopmental psychiatry disorders that exhibits emotional and cognitive impairments in adulthood following neonatal polyI:C treatment. In this study, we examined whether nicotine ameliorates emotional and cognitive impairments in the neonatal polyI:C model because recent studies have indicated the therapeutic benefits of nicotine in schizophrenia. Neonatal ICR mice were repeatedly injected with polyI:C ( $5 \mathrm{mg} / \mathrm{kg}$, s.c.) for 5 days (postnatal days 2 to 6$)$. At postnatal 10 weeks, emotional functions were analyzed in open field and social interaction tests. Cognitive function was analyzed in novel object recognition and prepulse inhibition (PPI) tests. PolyI:C-treated mice showed an increase in anxiety-like behaviors and impairments in social behaviors, object recognition memory, and PPI, compared with the vehicle-treated control group. Nicotine $(0.15$ and $0.5 \mathrm{mg} / \mathrm{kg}$, s.c.) dose-dependently improved polyI:C-induced impairments of emotional and cognitive behaviors, but had no effect on PPI deficit. The ameliorating effect of nicotine was antagonized by pretreatment with dihydro- $\beta$-erythroidine or methyllycaconitine. These results suggest that nicotine ameliorates emotional and cognitive impairments of the present polyI:C model through nicotinic acetylcholine receptors.
\end{abstract}

Keywords: Cognition, emotion, nicotine, polyI:C, schizophrenia, nicotinic acetylcholine receptors.

\section{INTRODUCTION}

Schizophrenia is a chronic psychiatric disorder characterized by positive and negative symptoms and impaired cognitive function, which affects approximately $1 \%$ of the general population [1]. Both genetic factors and environmental insults, including prenatal infection and perinatal complication, are involved in the development of schizophrenia [2]. Recent immunologic, epidemiologic, and neuropsychiatric studies suggest infectious etiologies of several major neuropsychiatric diseases [3]. Infectious organisms that have been implicated in schizophrenia etiology include rubella, influenza, herpes simplex virus, cytomegalovirus, poliovirus, and toxoplasma gondii [4].

Toll-like receptors (TLRs) constitute several families of the pattern-recognition receptors that sense nucleic acids derived from viruses and trigger antiviral innate immune

*Address correspondence to this author at the Department of Neuropsychopharmacology and Hospital Pharmacy, Nagoya University Graduate School of Medicine, 65 Tsuruma-cho, Showa-ku, Nagoya 4668560, Japan; Tel: +81-52-744-2674; Fax: +81-52-744-2979; E-mail: kyamada@med.nagoya-u.ac.jp

${ }^{\dagger}$ Contributed equally to the work. responses [5]. The TLR family consists of more than 13 members in mammals, each detecting different pathogenassociated molecular ligands [5]. In particular, TLR3 recognizes viral double-stranded RNA and host cell mRNA and in turn initiates inflammatory responses [6]. Polyriboinosinicpolyribocytidilic acid (polyI:C) is a synthetic analogue of double-stranded RNA that leads to the pronounced but timelimited production of pro-inflammatory cytokines after it binds to and activates TLR3 [7]. Maternal immune activation by polyI:C exposure in rodents is known to precipitate a wide spectrum of behavioral, cognitive, and pharmacological abnormalities in adult offspring [8-12]. Recently, we have reported that neonatal injection of polyI:C in mice results in schizophrenia-like behavioral alterations, such as emotional and cognitive impairments and dysfunction of glutamatergic neurotransmission in adulthood [13]. We have also proposed a possible interaction of genetic and environmental factors by injecting polyI:C into transgenic mice that express a dominant-negative form of human disrupted-in-schizophrenia 1, which is one of the susceptibility genes for schizophrenia [14]. Therefore, polyI:C-treated mice are the useful animal model for schizophrenia that is supported by epidemiological findings. 
Tobacco smoking is frequent among schizophrenia patients $[15,16]$. It has been reported that while $25-30 \%$ of the population smoke tobacco regularly, $70-90 \%$ of chronic schizophrenic patients are tobacco smokers $[17,18]$. Nicotine is a potent cholinergic receptor agonist that is inhaled during tobacco smoking. Interestingly, both the expression and function of nicotinic acetylcholine receptors (nAChRs) are down-regulated in the brains of patients with schizophrenia $[19,20]$. The enzyme activity of choline acetyltransferase, a biosynthetic enzyme for acetylcholine production is decreased and correlated with poor cognitive function in schizophrenia [21]. It is suggested that the high rate of tobacco smoking among schizophrenia patients represents an attempt to self-medicate, that is, to correct for some diseaseassociated abnormalities of cholinergic (nicotinic) neurotransmission. Thus, the therapeutic effects of nicotine in schizophrenia have received much interest in recent years.

In this study, to examine whether nicotine ameliorates emotional and cognitive impairments in adult mice that challenged with polyI: $\mathrm{C}$ as neonates, neurobehavioral effects of nicotine were analyzed in open field, social interaction, novel object recognition, and prepulse inhibition tests.

\section{MATERIALS AND METHODS}

\section{Animals}

Timed pregnant ICR mice were obtained from Japan SLC Inc. (Hamamatsu, Japan) and maintained under standard specific pathogen-free environmental conditions. Pregnant females were monitored for the parturition date, which was taken as postnatal day (PD) 0 . They were housed under a standard 12-h light/dark cycle (lights on at 9:00) at a constant temperature of $23 \pm 1{ }^{\circ} \mathrm{C}$, with free access to food and water throughout the experiments. We used male mice exclusively to minimize any potential variability due to sexspecific effects in behavioral performance. The animals were handled in accordance with the guidelines established by the Institutional Animal Care and Use Committee of Nagoya University, the Guiding Principles for the Care and Use of Laboratory Animals approved by the Japanese Pharmacological Society, and the National Institutes of Health Guide for the Care and Use of Laboratory Animals.

\section{Drugs and Treatment}

PolyI:C, (-)-nicotine, dihydro- $\beta$-erythroidine [DH $\beta E$, an antagonist for $\alpha 4 \beta 2$ subunit-containing $\mathrm{nAChR}(\alpha 4 \beta 2$ nAChR)], and methyllycaconitine [MLA, a selective antagonist for $\alpha 7$ subunit-containing nAChR ( $\alpha 7 \mathrm{nAChR})$ ] were purchased from Sigma-Aldrich (St Louis, MO, USA) and dissolved in saline. All litters were randomly divided into saline and polyI:C-treated groups. From PD 2 to 6, mice were subcutaneously injected daily with either pyrogen-free saline or polyI:C at a dose of $5 \mathrm{mg} / \mathrm{kg}$. Animals were weaned at PD 21, and divided by gender at PD 28. Both groups were derived from multiple litters to preclude possible differences in individual maternal behavior as a mitigating factor in any subsequent long-lasting changes induced in the offspring. Behavioral analyses were started at 10-12 weeks of age in the following order: prepulse inhibition (PPI), open field, novel object recognition test, and social interaction test for studying the effects of nicotine (Figs. 1-4); open field, novel object recognition test, and social interaction test for studying the effects of nAChR antagonists (Figs. 5-7). Nicotine $(0.15$ or $0.5 \mathrm{mg} / \mathrm{kg})$, DHßE $(2.0 \mathrm{mg} / \mathrm{kg})$, or MLA (5 $\mathrm{mg} / \mathrm{kg}$ ) was subcutaneously administered $15 \mathrm{~min}, 25 \mathrm{~min}$, or $25 \mathrm{~min}$, respectively, before behavioral tests. The dose of each drug was in accordance with previous reports $[22,23]$.

\section{Open Field Test}

Mice were placed at the center of an arena and allowed to explore an open field (diameter: $60 \mathrm{~cm}$, height: $35 \mathrm{~cm}$ ) for 5 min, while their activity was measured automatically using the ethovision automated tracking program (Brainscience Idea Co. Ltd., Osaka, Japan) $[24,25]$. The open field was divided into an inner circle (diameter: $40 \mathrm{~cm}$ ) and an outer area surrounding the inner circle. The movement of mice was measured via a camera mounted above the open field. Measurements included distance and time spent in the inner and outer sections.

\section{Social Interaction Test}

We used the experimental paradigm described by Tremolizzo et al. [26] to measure social behavior (e.g., social interaction, aggression, and escape behavior). PolyI:Ctreated or vehicle-treated control mice were individually housed in cages $(29 \times 18 \times 12 \mathrm{~cm})$ for 2 days before the trial. We used 10-12-week-old male ICR mice that had not shown aggressive behavior as intruders. In the first trial $(5 \mathrm{~min}$ duration), an intruder mouse was introduced into the resident's home cage. The duration of social interaction (close following, inspection, anogenital sniffing, and other social body contacts except aggressive behavior), aggression (attacking/biting and tail rattling), and escape behavior were analyzed. Four trials, with an inter-trial interval of $30 \mathrm{~min}$, were used to analyze social behavior using the same intruder mouse.

\section{Novel Object Recognition Test}

A novel object recognition test was carried out as described previously [27]. Mice were individually habituated to an open-box $(30 \times 30 \times 35$ high $\mathrm{cm})$ for 3 days. During the training session, two novel objects were placed in the open field and the animals were allowed to explore for 10 min. The time spent exploring each object was recorded. During retention sessions, the animals were placed back into the same box $24 \mathrm{~h}$ after the training session, one of the familiar objects used during training was replaced by a novel object, and the mice were allowed to explore the two objects freely for $5 \mathrm{~min}$. The preference index in the retention session, the ratio of the amount of time spent exploring the novel object to the total time spent exploring both objects, was used to measure cognitive function. In the training session, the preference index was calculated as the ratio of time spent exploring the object that was replaced by a novel object in the retention session to the total exploration time.

\section{PPI Test}

The PPI test was carried out as described previously [28, 29]. After the animals were placed in the chamber (San Diego Instruments, San Diego, California), they were allowed to habituate for $10 \mathrm{~min}$, during which time they 
A

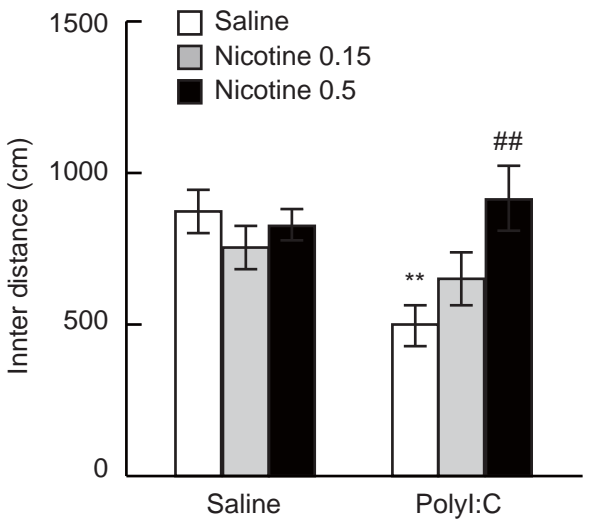

B

Outer distance

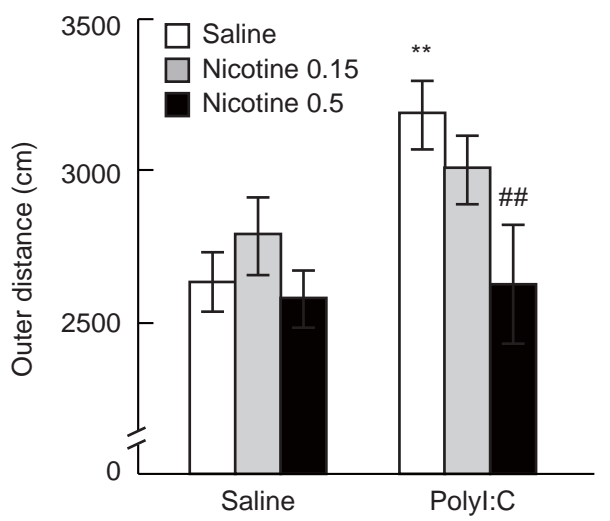

Fig. (1). Effect of nicotine on emotional deficits in open field test in polyI:C-treated mice. Nicotine $(0.15 \mathrm{and} 0.5 \mathrm{mg} / \mathrm{kg}$, s.c.) was administered $15 \mathrm{~min}$ before the behavioral test. Individual mice were allowed to explore the open field freely for 5 min. (A and B) Distance traveled in (A) inner and (B) outer sectors. Values indicated the mean \pm S.E. $(n=8-10) .{ }^{*} \mathrm{p}<0.01 v s$. saline-treated control group (Fisher's LSD test). \#\# $\mathrm{p}<0.01 \mathrm{vs}$. polyI:C-treated control group (Fisher's LSD test).

were subjected to $65 \mathrm{~dB}$ background white noise. The animals then received 10 startle trials, 10 no-stimulus trials, and 40 PPI trials. The intertrial interval was between 10 and $20 \mathrm{sec}$ and the total session lasted $17 \mathrm{~min}$. The startle trial consisted of a single $120 \mathrm{~dB}$ white noise burst lasting 40 msec. PPI trials consisted of a prepulse $(20 \mathrm{msec}$ burst of white noise at $69,73,77$, or $81 \mathrm{~dB}$ intensity) followed, 100 msec later, by the startle stimulus $(120 \mathrm{~dB}, 40 \mathrm{msec}$ white noise). Each of the four prepulse trials $(69,73,77$, or $81 \mathrm{~dB})$ was carried out 10 times. Sixty different trials were presented pseudo-randomly, ensuring that each trial was carried out 10 times and that no two consecutive trials were identical. The resulting movement of the animal in the startle chamber was measured for $100 \mathrm{msec}$ after startle stimulus onset (sampling frequency $1 \mathrm{kHz}$ ), rectified, amplified, and fed into a computer, which calculated the maximal response over the 100 msec. Basal startle amplitude was determined as the mean amplitude of the 10 startle trials. PPI was calculated according to the formula: $100 \times[1-(\mathrm{PPx} / \mathrm{P} 120)]$ $\%$, in which PPx was the mean amplitude of the 10 PPI trials (PP69, PP73, PP75, or PP80) and P120 was the basal startle amplitude.

\section{Statistical Analysis}

Data are expressed as the mean \pm S.E. Statistical significance was determined using analysis of variance (ANOVA) with two-way (Figs. 1-3 and 4B) or three-way (Fig. 4A), followed by the Fisher's LSD test when F ratios were significant $(\mathrm{p}<0.05)$. In Figs. (5-7), two-tailed Student's t-test was used between the saline-treated polyI:C and control (saline + saline) groups while two-way ANOVA was performed among polyI:C-treated groups.

\section{RESULTS}

Effects of Nicotine on Emotional Deficits in PolyI:CTreated Mice in Open Field Test

To investigate the effects of nicotine on emotional deficits in polyI:C-treated mice in adulthood, an open field test was carried out at the age of 10-12 weeks, in which the conflict between the drive to explore a new environment and a natural aversion to illuminated open areas was used to examine both anxiety and motor activity [25]. Two-way ANOVA revealed significant effects of polyI:C and nicotine in distance traveled in inner sectors (polyI: $\mathrm{C}, \mathrm{F}(1,47)=4.24$, $\mathrm{p}<0.05$; nicotine, $\mathrm{F}(2,47)=3.45, \mathrm{p}<0.05$; polyI: $\mathrm{C} \times$ nicotine interaction, $F(2,47)=4.73, p<0.05$, Fig. 1A) and outer sectors (polyI:C, $\mathrm{F}(1,47)=4.17, \mathrm{p}<0.05 ;$ nicotine, $\mathrm{F}(2,47)=5.10$, $\mathrm{p}<0.01$; polyI $\mathrm{C} \times$ nicotine interaction, $\mathrm{F}(2,47)=2.50, \mathrm{p}=0.09$, Fig. 1B) of the open field. The distance traveled in the inner sector of the open field was significantly decreased while the distance traveled in the outer sector was significantly increased in polyI:C-treated mice compared with vehicle-treated control mice $(p<0.01$, Fig. $\mathbf{1 A}$ and $\mathbf{B})$. Nicotine dosedependently and significantly $(0.5 \mathrm{mg} / \mathrm{kg})$ increased the distance traveled in the inner sector $(\mathrm{p}<0.01$, Fig. 1A), and decreased the distance traveled in the outer sector in polyI:Ctreated mice $(p<0.01$, Fig. 1B). Likewise, nicotine $(0.5$ $\mathrm{mg} / \mathrm{kg}$ ) treatment tended to ameliorate the changes in time spent in inner and outer sectors of the open field in polyI:Ctreated mice (data not shown). Nicotine itself had no effect on performance in the saline-treated control group (Fig. 1), suggesting that nicotine has no effect on motor function in mice. These results suggest that nicotine ameliorates polyI:C-induced emotional deficits in adults.

\section{Effects of Nicotine on Deficits of Social Behavior in PolyI:C-Treated Mice}

Social interaction in polyI:C-treated mice was investigated at the age of 10-12 weeks. In saline-treated control mice, repeated exposure to an unfamiliar intruder mouse (4 trials) caused a gradual decrease in social interaction time. The polyI:C-treated mice exhibited a marked reduction in the social interaction time in all 4 trials compared with salinetreated control mice (data not shown). Therefore, total social interaction time was evaluated in the following analysis. Two-way ANOVA revealed significant effects of polyI:C and nicotine in social interaction (polyI:C, $\mathrm{F}(1,47)=25.27$, 
A

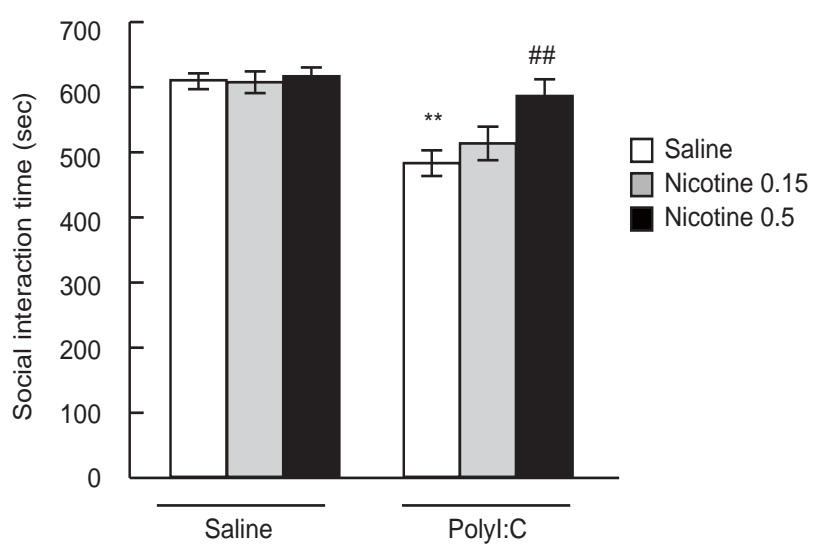

C

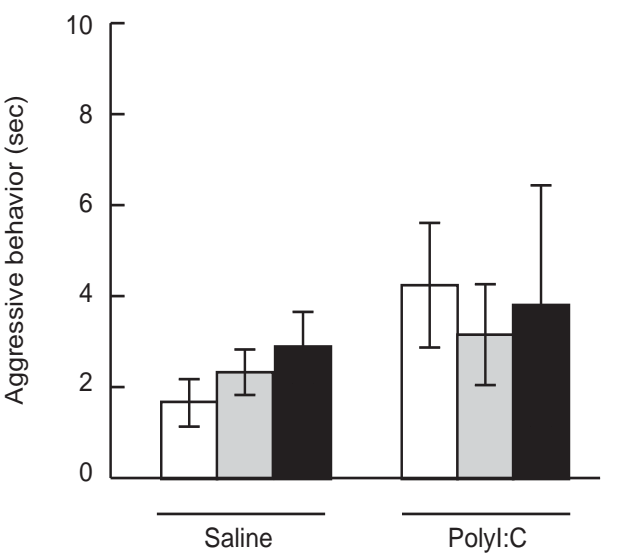

Fig. (2). Effect of nicotine on deficits of social behaviors in social interaction test in polyI:C-treated mice. (A) Social interaction, (B) escape behavior, and $(\mathbf{C})$ aggressive behavior. Nicotine $(0.15$ and $0.5 \mathrm{mg} / \mathrm{kg}$, s.c.) was administered $15 \mathrm{~min}$ before the behavioral test. Values indicate the mean \pm S.E. $(n=8-10)$. $* * p<0.01 v s$. salinetreated control group (Fisher's LSD test). \#\# $\mathrm{p}<0.01$ vs. polyI:Ctreated control group (Fisher's LSD test). $\mathrm{p}<0.01$; nicotine, $\mathrm{F}(2,47)=3.82, \mathrm{p}<0.05$; polyI $\mathrm{C} \times$ nicotine interaction, $F(2,47)=3.06, p=0.06$, Fig. 2A). These treatments had no effects on escape (polyI:C, $\mathrm{F}(1,47)=0.68, \mathrm{p}=0.41$; nicotine, $\mathrm{F}(2,47)=0.08, \mathrm{p}=0.92$; polyI $\mathrm{C} \times$ nicotine interaction, $\mathrm{F}(2,47)=1.98, \mathrm{p}=0.15$, Fig. $2 \mathrm{~B}$ ) or aggressive behavior (polyI:C, $\mathrm{F}(1,47)=1.56, \mathrm{p}=0.22$; nicotine, $\mathrm{F}(2,47)=0.09$, $\mathrm{p}=0.92$; polyI $\mathrm{C} \times$ nicotine interaction, $\mathrm{F}(2,47)=0.26, \mathrm{p}=0.77$, Fig. 2C). A single treatment with nicotine $(0.5 \mathrm{mg} / \mathrm{kg})$ significantly improved deficits of social interaction in polyI:Ctreated mice $(p<0.01$, Fig. 2A) without affecting escape (Fig. 2B) or aggressive behavior (Fig. 2C). In saline-treated mice, nicotine $(0.15$ and $0.5 \mathrm{mg} / \mathrm{kg})$ had no effect on social interaction (Fig. 2A), escape (Fig. 2B), or aggressive behavior (Fig. 2C). These results suggest that the ameliorating effect of nicotine on social interaction deficit is not due to locomotor stimulation by the drugs or to changes in escape or aggressive behavior of polyI:C-treated mice.

\section{Effects of Nicotine on Deficits of Object Recognition Memory in PolyI:C-Treated Mice}

To examine the effects of nicotine treatment on neonatal polyI:C treatment-induced memory impairment in adults, a novel object recognition test was carried out at the age of 1012 weeks. During the training session, both polyI:C-treated and saline-treated control mice spent equal amounts of time exploring either one of two objects (two-way ANOVA analysis; polyI:C, $\mathrm{F}(1,42)=1.48, \quad \mathrm{p}=0.23$; nicotine $\mathrm{F}(2,42)=2.62, \mathrm{p}=0.09$; polyI $\mathrm{C} \times$ nicotine interaction, $\mathrm{F}(2,42)$ $=0.04, p=0.96$, Fig. 3B), and there was no biased exploratory preference in either group (two-way ANOVA analysis; polyI:C, $\mathrm{F}(1,42)=0.01, \mathrm{p}=0.95 ;$ nicotine $\mathrm{F}(2,42)=0.28$, $\mathrm{p}=0.76$; polyI $\mathrm{C} \times$ nicotine interaction, $\mathrm{F}(2,42)=0.05, \mathrm{p}=0.95$, Fig. 3A), suggesting no differences in motivation and curiosity about novel objects, and motor function between polyI:C-treated and saline-treated control mice. The retention session was carried out $24 \mathrm{~h}$ after the training session. Twoway ANOVA indicated that significant effects of polyI:C and nicotine were detected in the level of exploratory preference to the novel object (polyI:C, $\mathrm{F}(1,42)=51.72$, $\mathrm{p}<0.01$; nicotine $\mathrm{F}(2,42)=11.07, \mathrm{p}<0.01$; polyI: $\mathrm{C} \times$ nicotine interaction, $\mathrm{F}(2,42)=8.70, \mathrm{p}<0.01$, Fig. 3A). The level of exploratory preference to the novel object was significantly decreased in polyI:C-treated mice compared with salinetreated control mice $(p<0.01$, Fig. 3A). Total exploration time in the retention session did not differ among the groups (two-way ANOVA analysis; polyI: $\mathrm{C}, \mathrm{F}(1,42)=3.70, \mathrm{p}=0.06$; nicotine $\mathrm{F}(2,42)=0.35, \mathrm{p}=0.71$; polyI $\mathrm{C} \times$ nicotine interaction, $F(2,42)=0.08, p=0.92$, Fig. 3B), indicating that polyI:Ctreated mice are unable to discriminate novel and familiar objects. These results suggest that polyI:C-treated mice have impaired recognition memory in adulthood. A single treatment with nicotine $(0.5 \mathrm{mg} / \mathrm{kg})$ significantly improved cognitive impairment in polyI:C-treated mice during the retention session $(p<0.01$, Fig. 3A) when nicotine was administered $15 \mathrm{~min}$ before the training session. Nicotine had no effect on the level of exploratory preference to the novel object in the training session in polyI:C-treated mice (Fig. 3A). The total exploration time in polyI:C-treated mice was not affected by nicotine in either training or retention session (Fig. 3B). In saline-treated mice, nicotine had no effect on the level of exploratory preference or total exploration time throughout the experiment (Fig. 3A and B). 
A

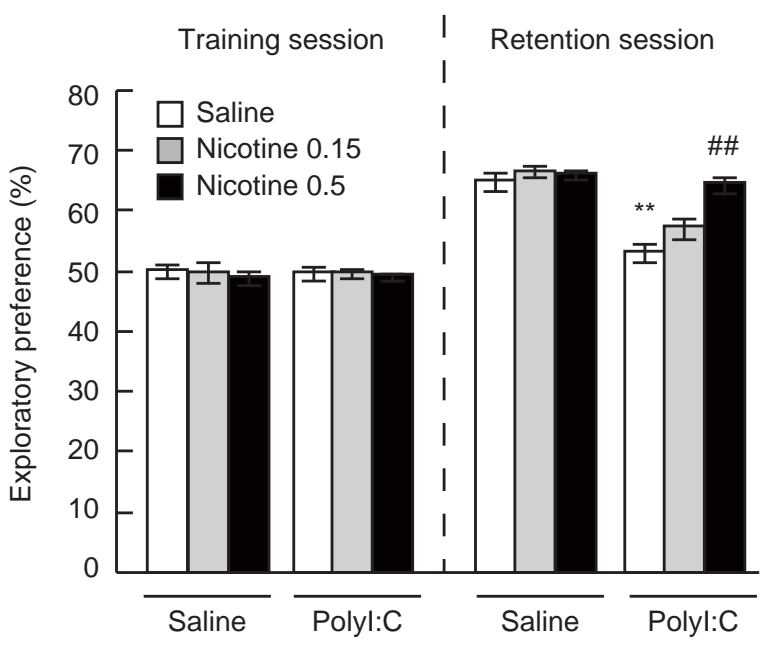

B

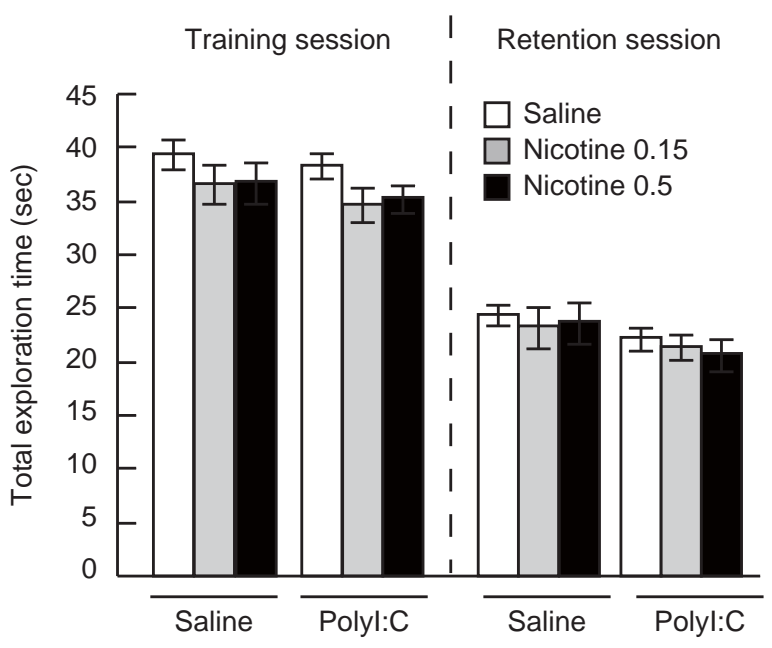

Fig. (3). Effect of nicotine on deficits of object recognition memory in novel object recognition test in polyI:C-treated mice. (A) Exploratory preference. (B) Total exploration time. Nicotine $(0.15$ and $0.5 \mathrm{mg} / \mathrm{kg}$, s.c.) was administered $15 \mathrm{~min}$ before the training session. The retention session was carried out $24 \mathrm{~h}$ after the training session. Values indicate the mean \pm S.E. $(\mathrm{n}=8)$. ${ }^{* *} \mathrm{p}<0.01 v$ s. salinetreated control group (Fisher's LSD test). \#\# $\mathrm{p}<0.01$ vs. polyI:Ctreated control group (Fisher's LSD test).

\section{Effects of Nicotine on PPI Deficits of Startle Response in PolyI:C-Treated Mice}

The PPI test was carried out at the age of 10-12 weeks to assess the sensorimotor gating function in polyI:C-treated mice. Three-way ANOVA revealed that significant effects of polyI:C, but no significant effects of nicotine was detected in PPI test (polyI:C, $\mathrm{F}(1,42)=72.16, \mathrm{p}<0.01$; nicotine, $\mathrm{F}(2,42)=$ $0.21, \mathrm{p}=0.81$; polyI: $\mathrm{C} \times$ nicotine interaction, $\mathrm{F}(2,42)=0.14$, $\mathrm{p}=0.87$; prepulse, $\mathrm{F}(3,126)=55.26, \mathrm{p}<0.01$; polyI:C $\times$ prepulse interaction, $\mathrm{F}(3,126)=16.36, \mathrm{p}<0.01$; nicotine $\times$ prepulse interaction, $\mathrm{F}(3,126)=0.18, \mathrm{p}=0.98$; polyI:C $\times$ nicotine $\times$ prepulse interaction, $\mathrm{F}(3,126)=0.67, \mathrm{p}=0.67)$. PolyI:C-treated mice showed a marked impairment of PPI compared with the saline-treated control group at the prepulse intensities $(69,73,77$ and $81 \mathrm{~dB}) \quad(\mathrm{p}<0.05$ or $\mathrm{p}<0.01$, Fig. 4A). Single treatment with nicotine $(0.15$ and $0.5 \mathrm{mg} / \mathrm{kg}$ ) had no effect on PPI deficits (Fig. 4A) or acoustic startle amplitude in the polyI:C-treated group nor in the saline-treated control group (two-way ANOVA analysis; polyI:C, $\mathrm{F}(1,42)=0.06, \quad \mathrm{p}=0.80 ;$ nicotine, $\mathrm{F}(2,42)=0.05$, $\mathrm{p}=0.95$; polyI $\mathrm{C} \times$ nicotine, $\mathrm{F}(2,42)=0.11, \mathrm{p}=0.89$, Fig. 4B).

\section{Effects of nAChR Antagonists on Ameliorative Effect of Nicotine Against Emotional and Cognitive Deficits in PolyI:C-Treated Mice}

To clarify the subtype of nAChRs involved in the ameliorative effect of nicotine on the emotional and cognitive deficits in polyI:C-treated mice, the mice were pretreated with a selective antagonist for $\alpha 7 \mathrm{nAChR}$, MLA, or an antagonist for $\alpha 4 \beta 2 \mathrm{nAChR}, \mathrm{DH} \beta \mathrm{E}$, before nicotine treatment.

In the open field test, two-way ANOVA revealed significant differences in distance traveled in inner sectors (nicotine, $\mathrm{F}(1,50)=0.01, \mathrm{p}=0.93 ; \mathrm{nAChR}$ antagonists, $\mathrm{F}(2,50)=$ $0.20, \mathrm{p}=0.82$; nicotine $\times \mathrm{nAChR}$ antagonists interaction, $\mathrm{F}(2,50)=5.91, \mathrm{p}<0.01$, Fig. $\mathbf{5 A}$ ) and outer sectors (nicotine, $\mathrm{F}(1,50)=15.96, \mathrm{p}<0.01$; nAChR antagonists, $\mathrm{F}(2,50)=6.83$, $\mathrm{p}<0.01$; nicotine $\times \mathrm{nAChR}$ antagonists interaction, $F(2,50)=0.76, p=0.47$, Fig. 5B). The ameliorating effect of nicotine on anxiety-like behavioral changes in polyI:Ctreated mice was completely blocked by pretreatment with either MLA or DH $\beta E(p<0.05$, Fig. 5A and B). Treatment with MLA or DH $\beta E$ alone did not affect the change in distance traveled in the inner or outer sector for salinetreated polyI:C mice (Fig. 5A and B). Similar results were observed in the change in time spent in each sector (data not shown).

In the social interaction test, pretreatment with MLA or DHBE significantly attenuated the ameliorating effect of nicotine in polyI:C-treated mice although the same treatment failed to affect saline-treated polyI: $\mathrm{C}$ mice (nicotine, $\mathrm{F}(1,50)$ $=8.94, \mathrm{p}<0.01 ; \mathrm{nAChR}$ antagonists, $\mathrm{F}(2,50)=4.80, \mathrm{p}<0.05$; nicotine $\times \mathrm{nAChR}$ antagonists interaction, $\mathrm{F}(2,50)=2.63$, $\mathrm{p}=0.08$, Fig. 6A). Furthermore, nAChR antagonists had no effect on escape (nicotine, $\mathrm{F}(1,50)=0.05, \mathrm{p}=0.82$; nAChR antagonists, $\mathrm{F}(2,50)=0.01, \mathrm{p}=0.99 ;$ nicotine $\times \mathrm{nAChR}$ antagonists interaction, $F(2,50)=0.23, p=0.80$, Fig. 6B) or aggressive behaviors (nicotine, $\mathrm{F}(1,50)=0.54, \mathrm{p}=0.47$; $\mathrm{nAChR}$ antagonists, $\mathrm{F}(2,50)=0.07, \mathrm{p}=0.93$; nicotine $\times$ $\mathrm{nAChR}$ antagonists interaction, $\mathrm{F}(2,50)=0.12, \mathrm{p}=0.89$, Fig. 6C) in either saline-treated or nicotine-treated polyI:C mice.

In the novel object recognition test, MLA and DHßE significantly and completely blocked the ameliorating effect of nicotine on the impairment of object recognition memory in polyI:C-treated mice (nicotine, $\mathrm{F}(1,50)=10.85, \mathrm{p}<0.01$; nAChR antagonists, $\mathrm{F}(2,50)=3.66, \mathrm{p}<0.05$; nicotine $\times$ $\mathrm{nAChR}$ antagonists interaction, $\mathrm{F}(2,50)=5.65, \mathrm{p}<0.01$, Fig. 7A). Treatment with MLA or DH $\beta E$ did not affect the exploratory preference in saline-treated mice or the total 

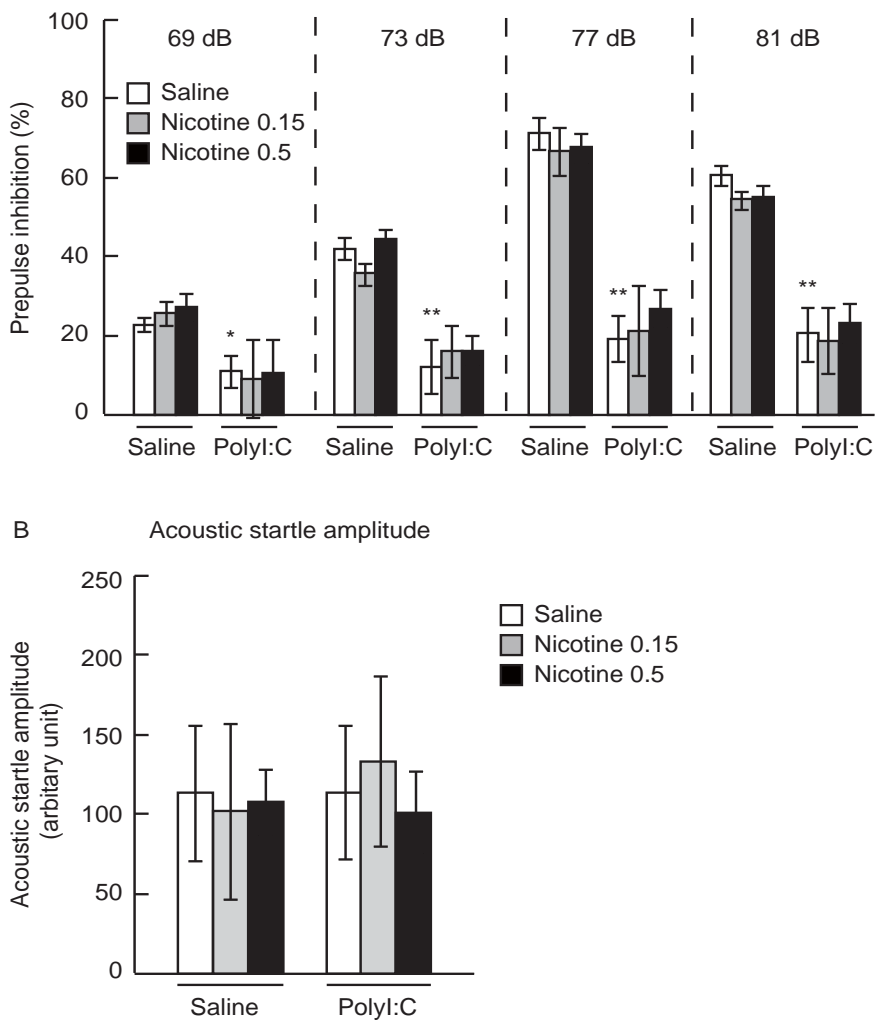

Fig. (4). Effect of nicotine on PPI deficits of startle response in polyI:C-treated mice. (A) PPI (\%) at four different prepulse intensities (69, 73, 77, and $81 \mathrm{~dB})$. (B) Acoustic startle amplitude as measured in trials without prepulse. Nicotine $(0.15 \mathrm{and} 0.5 \mathrm{mg} / \mathrm{kg}$, s.c.) was administered $15 \mathrm{~min}$ before the behavioral test. Values indicate the mean \pm S.E. $(\mathrm{n}=8)$. ${ }^{*} \mathrm{p}<0.05$ and $* * \mathrm{p}<0.01$ vs. saline-treated control group (Fisher's LSD test).
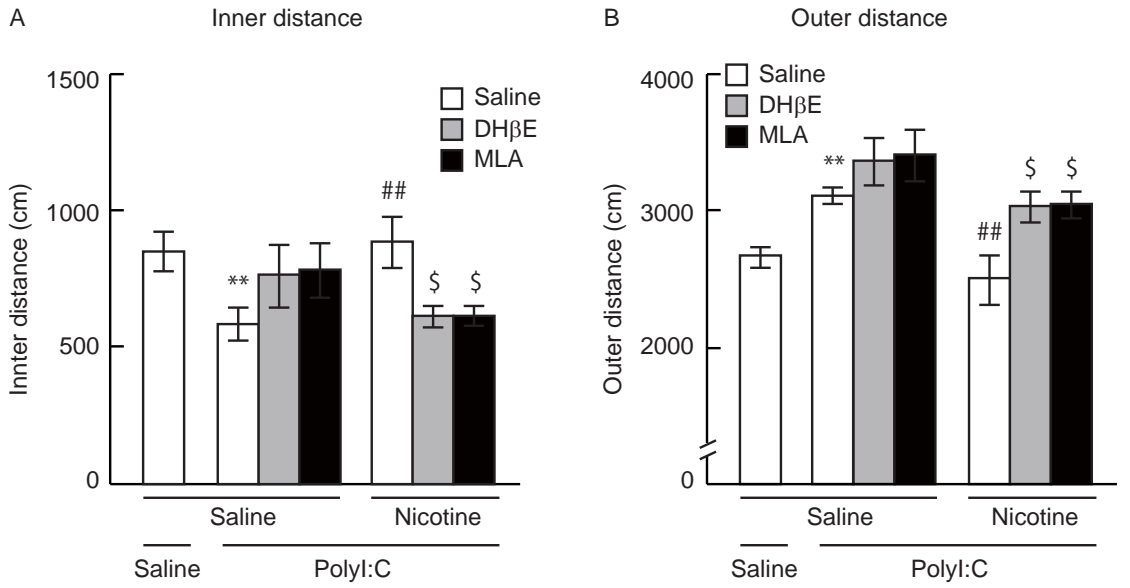

Fig. (5). Effects of $n A C h$ receptor antagonists on nicotine-induced amelioration of emotional deficits in polyI:C-treated mice. $\alpha 4 \beta 2 \mathrm{nACh}$ receptor antagonist $\mathrm{DH} \beta \mathrm{E}(2.0 \mathrm{mg} / \mathrm{kg}$, s.c.) or $\alpha 7 \mathrm{nACh}$ receptor antagonist MLA $(5 \mathrm{mg} / \mathrm{kg}$, s.c. $)$ was administered $25 \mathrm{~min}$ before the behavioral test. Nicotine $(0.5 \mathrm{mg} / \mathrm{kg}$, s.c. $)$ was administered $15 \mathrm{~min}$ before the behavioral test. Individual mice were allowed to explore the open field freely for $5 \mathrm{~min}$. (A and B) Distance traveled in (A) inner and (B) outer sectors. Values indicate the mean \pm S.E. ( $\mathrm{n}=8-16$ ). $*^{* *} \mathrm{p}<0.01$ vs. saline-treated control group (Student's $t$-test). \#\#p $<0.01$ vs. saline-treated polyI:C group (Fisher's LSD test). $\$ \mathrm{p}<0.05$ vs. nicotine-treated polyI:C group (Fisher's LSD test).

exploration time in either the training or retention sessions in all groups (Fig. 7A and $\mathbf{B}$ ).

\section{DISCUSSION}

It has been reported that the first 2 weeks of postnatal life in the rat and mouse correspond to the second trimester of pregnancy in humans [30], during which time exposure to viral or environmental insult increases the probability of subsequently developing schizophrenia in adolescence. This period is a critical time for neurogenesis in the hippocampus, and for cortical synaptogenesis [31]. According to these findings, we have developed a mouse model of viral infection during the perinatal period by repeatedly injecting 
A

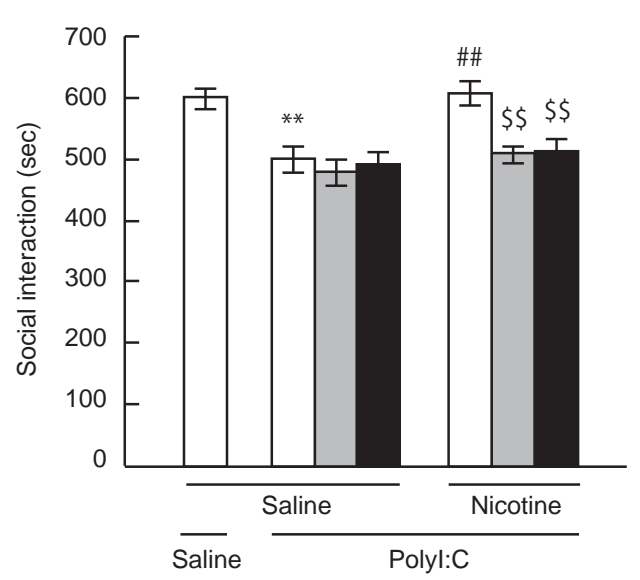

B

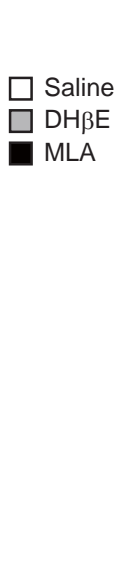

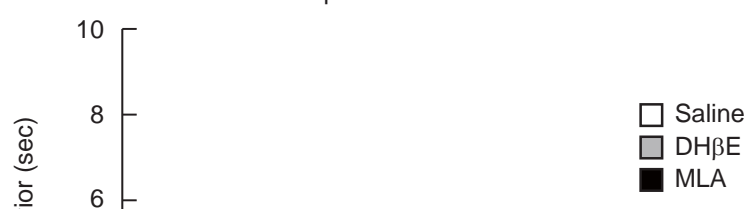

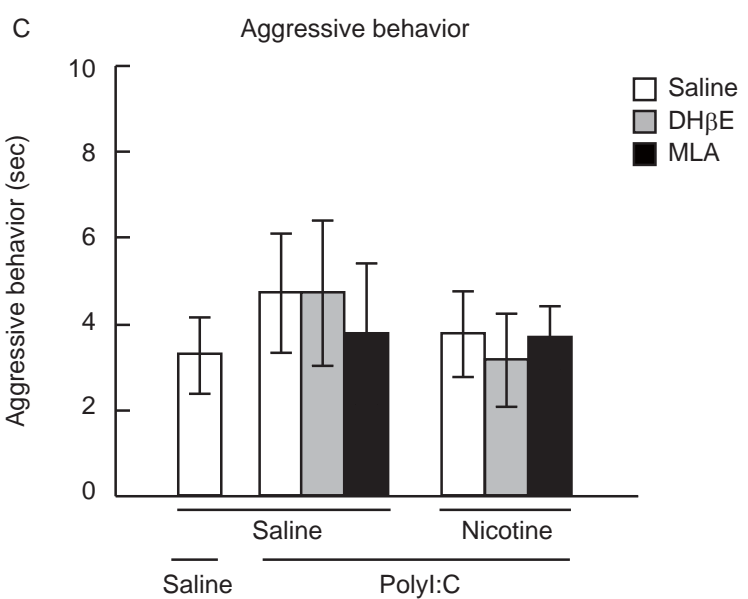

Fig. (6). Effects of nACh receptor antagonists on nicotine-induced amelioration of deficits of social behaviors in polyI:C-treated mice. (A) Social interaction, (B) escape behavior, and (C) aggressive behavior. $\alpha 4 \beta 2 \mathrm{nACh}$ receptor antagonist DH $\beta \mathrm{E}(2.0 \mathrm{mg} / \mathrm{kg}, \mathrm{s.c}$.) or $\alpha 7 \mathrm{nACh}$ receptor antagonist MLA (5 mg/kg, s.c.) was administered $25 \mathrm{~min}$ before the behavioral test. Nicotine $(0.5 \mathrm{mg} / \mathrm{kg}$, s.c.) was administered 15 min before the behavioral test. Values indicate the mean \pm S.E. $(\mathrm{n}=8-16) .{ }^{*} \mathrm{p}<0.01 v s$. saline-treated control group (Student's $t$-test). $\# \# \mathrm{p}<0.01$ vs. saline-treated polyI:C group (Fisher's LSD test). $\$ \$ \mathrm{p}<0.01$ vs. nicotine-treated polyI:C group (Fisher's LSD test).

polyI:C into neonatal ICR mice at postnatal days 2 to 6 [13]. Consistent with our previous study, polyI:C-treated mice showed anxiety-like behavior in the open field test, impaired social behavior in the social interaction test, impaired recognition memory in the novel object recognition test, and sensorimotor gating deficits in the PPI test after puberty. These results suggest that neonatal polyI:C treatment in ICR mice can provide an animal model exhibiting schizophrenialike behavioral phenotypes after puberty. The abnormal behaviors, except for PPI deficits, in polyI:C-treated mice were ameliorated by the treatment with nicotine in a dosedependent manner. Thus nicotine may have a therapeutic benefit in ameliorating clinical symptoms in schizophrenia. It is plausible that neonatal polyI:C treatment interferes in the development of cholinergic neurons, leading to abnormal behaviors in adulthood since the early postnatal period is the time for the entry of cholinergic fibers into the cortex [31].

Nicotine failed to improve the PPI deficits in polyI:Ctreated mice while smoking transiently normalizes sensory gating deficits in schizophrenia [32]. Studies in rodents have shown that $\alpha 7 \mathrm{nAChR}$ antagonists induce PPI deficits while $\alpha 7$ nAChR agonists can normalize the auditory gating deficits [33, 34]. The reason for this discrepancy remains unclear. It is unlikely that polyI:C-treated mice lack predictive validity as an animal model of schizophrenia. Because the emotional and cognitive impairments including PPI deficits in polyI:C-treated mice were ameliorated by the treatment of typical and atypical antipsychotics such as haloperidol and clozapine, respectively (data not shown). Alternatively, it is well known that dopamine receptor agonists disrupt PPI of the startle reflex [35]. Therefore, activation of dopaminergic neurons by nicotine [36] may hide the beneficial effect of nicotine on sensorimotor gating in polyI:C-treated mice.

nAChRs are pentameric, ligand-gated ion channels abundant in the central nervous system [37]. Twelve neuronal subunits have been identified, designated $\alpha 2$ to $\alpha 10$ and $\beta 2$ to $\beta 4$, which potentially assemble in multiple combinations with a broad range of pharmacological and electrophysiological properties [38]. In particular, the two most prevalent 

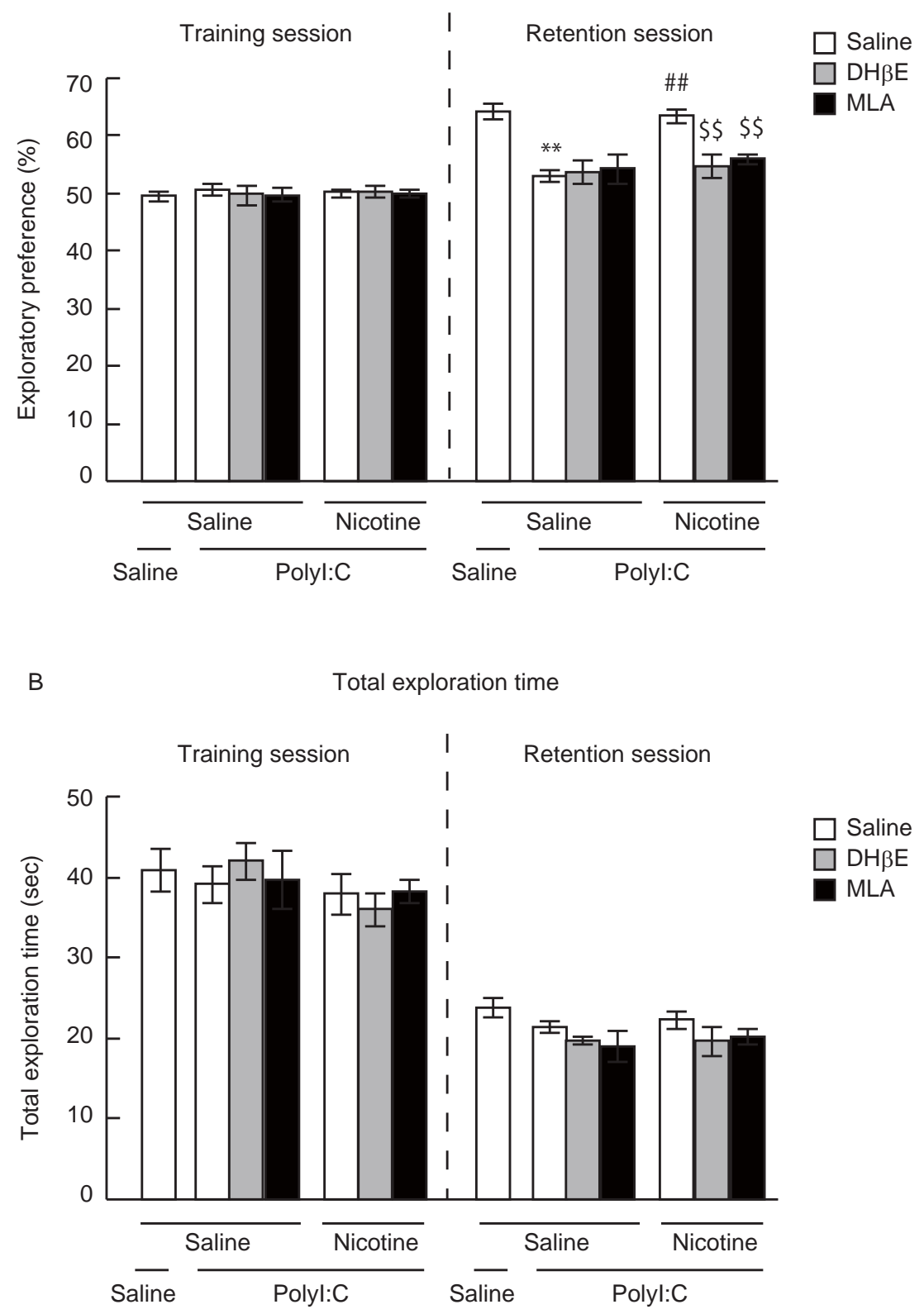

Fig. (7). Effects of $\mathrm{nACh}$ receptor antagonists on nicotine-induced amelioration of recognition memory impairment in polyI:C-treated mice. (A) Exploratory preference. (B) Total exploration time. $\alpha 4 \beta 2 \mathrm{nACh}$ receptor antagonist DH $\beta \mathrm{E}(2.0 \mathrm{mg} / \mathrm{kg}$, s.c.) or $\alpha 7 \mathrm{nACh}$ receptor antagonist MLA $(5 \mathrm{mg} / \mathrm{kg}$, s.c.) was administered $25 \mathrm{~min}$ before the training session. Nicotine $(0.5 \mathrm{mg} / \mathrm{kg}$, s.c.) was administered $15 \mathrm{~min}$ before the training session. The retention session was carried out $24 \mathrm{~h}$ after the training session. Values indicate the mean $\pm \mathrm{S} . \mathrm{E}$. $(\mathrm{n}=8-16)$. $* * \mathrm{p}<0.01$ vs. saline-treated control group (Student's $t$-test). \#\#p $<0.01$ vs. saline-treated polyI:C group (Fisher's LSD test). $\$ \$ \mathrm{p}<0.01$ vs. nicotine-treated polyI:C group (Fisher's LSD test).

receptors are high-affinity $\alpha 4 \beta 2 \mathrm{nAChR}$ and low-affinity $\alpha 7$ nAChR. High numbers of $\alpha 4 \beta 2$ and $\alpha 7 \mathrm{nAChR}$ binding sites have been observed in several brain regions during the early developmental period $[39,40]$. In the present study, we found that both antagonists for $\alpha 4 \beta 2$ and $\alpha 7 \mathrm{nAChRs}$ completely blocked the effect of nicotine on anxiety, and social interaction and memory deficits in polyI:C-treated mice. These results suggest that the ameliorating effects of nicotine on abnormal behaviors in polyI:C-treated mice are mediated by the activation of $\alpha 4 \beta 2$ and $\alpha 7 \mathrm{nAChRs}$.
It has been reported that the number of $\alpha 7 \mathrm{nAChRs}$ is reduced in patients with schizophrenia $[19,41]$. Functional polymorphisms have been identified in the promoter region of the $\alpha 7 \mathrm{nAChR}$ gene, which are associated with schizophrenia risk [42, 43]. In addition to $\alpha 7 \mathrm{nAChR}$, decreased levels of $\alpha 4 \beta 2 \mathrm{nAChR}$ binding have been found in the hippocampus of patients with schizophrenia [19]. $\alpha 4 \beta 2$ $\mathrm{nAChR}$ agonists can produce a significant and long-lasting improvement of memory in aged rats and monkeys [44]. Taken together, these findings suggest that $\alpha 4 \beta 2$ and $\alpha 7$ 
nAChRs might be molecular targets for treatment in schizophrenia.

The mechanisms by which nicotine ameliorates the schizophrenia-like behaviors via $\alpha 4 \beta 2$ and $\alpha 7 \mathrm{nAChRs}$ remain to be determined. It is known, however, that presynaptic $\alpha 4 \beta 2$ and $\alpha 7 \mathrm{nAChRs}$ stimulate neurotransmitter release, mainly dopamine, glutamate, serotonin, and noradrenaline neurotransmitters [45-49]. Interestingly, our previous study demonstrated that depolarization-evoked glutamate release in the hippocampus of polyI:C-treated mice is significantly lower than the response in saline-treated control mice [13]. Therefore, it is possible that stimulation of $\alpha 4 \beta 2$ and $\alpha 7$ nAChRs may trigger glutamate release, contributing to the ameliorating effect of nicotine on emotional and cognitive dysfunction in polyI:C-treated mice. This issue should be resolved in further research.

In conclusion, single treatment with nicotine ameliorated various schizophrenia-like behavioral deficits in polyI:Ctreated mice in adulthood although it had no effect on PPI deficits. The antipsychotic effects of nicotine were blocked by $\alpha 4 \beta 2$ and $\alpha 7 \mathrm{nAChR}$ antagonists. These results support the hypothesis that nicotine may have some therapeutic benefits in treating clinical symptoms in schizophrenia.

\section{ACKNOWLEDGEMENTS}

We thank Dr. N. Ogiso and the staff at the Division of Experimental Animals, Nagoya University, for their technical assistance. This study was supported in part by a Grantin-Aid for Scientific Research (No. 19390062, 21790067) from the JSPS, Research on the Risk of Chemical Substances, Health and Labor Science Grants supported by the Ministry of Health, Labour and Welfare, the CREST from JST, the MEXT Global-COE Program, Academic Frontier Project for Private Universities, a matching fund subsidy from MEXT, 2007-2011, Regional Joint Research Program supported by grants to Private Universities to Cover Current Expenses from MEXT, and grants from the Smoking Research Foundation.

\section{REFERENCES}

[1] Rössler W, Salize HJ, van Os J, Riecher-Rössler A. Size of burden of schizophrenia and psychotic disorders. Eur Neuropsychopharmacol 2005; 15: 399-409.

[2] Lang UE, Puls I, Muller DJ, Strutz-Seebohm N, Gallinat J. Molecular mechanisms of schizophrenia. Cell Physiol Biochem 2007; 20: 687-702.

[3] Yolken RH, Karlsson H, Yee F, Johnston-Wilson NL, Torrey EF. Endogenous retroviruses and schizophrenia. Brain Res Rev 2000; 31: 193-9.

[4] Brown AS, Susser ES. In utero infection and adult schizophrenia. Ment Retard Dev Disabil Res Rev 2002; 8: 51-7.

[5] Kawai T, Akira S. Toll-like receptor and RIG-I-like receptor signaling. Ann NY Acad Sci 2008; 1143: 1-20.

[6] Kawai T, Akira S. Innate immune recognition of viral infection. Nat Immunol 2006 7; 131-7.

[7] Wang T, Town T, Alexopoulou L, Anderson JF, Fikrig E, Flavell RA. Toll-like receptor 3 mediates West Nile virus entry into the brain causing lethal encephalitis. Nat Med 2004; 10: 1366-73.

[8] Shi L, Fatemi SH, Sidwell RW, Patterson PH. Maternal influenza infection causes marked behavioral and pharmacological changes in the offspring. J Neurosci 2003; 23: 297-302.

[9] Meyer U, Feldon J, Schedlowski M, Yee BK. Towards an immunoprecipitated neurodevelopmental animal model of schizophrenia. Neurosci Biobehav Rev 2005; 29: 913-47.
[10] Meyer U, Nyffeler M, Engler A, et al. The time of prenatal immune challenge determines the specificity of inflammation-mediated brain and behavioral pathology. J Neurosci 2006; 26: 4752-62.

[11] Patterson PH. Maternal effects on schizophrenia risk. Science 2007; 318: 576-77.

[12] Cameron JS, Alexopoulou L, Sloane JA, et al. Toll-like receptor 3 is a potent negative regulator of axonal growth in mammals. $\mathrm{J}$ Neurosci 2007; 27: 13033-41.

[13] Ibi D, Nagai T, Kitahara Y, et al. Neonatal polyI:C treatment in mice results in schizophrenia-like behavioral and neurochemical abnormalities in adulthood. Neurosci Res 2009; 64: 297-305.

[14] Ibi D, Nagai $T$, Koike $H$, et al. Combined effect of neonatal immune activation and mutant DISC1 on phenotypic changes in adulthood. Behav Brain Res 2010; 206: 32-7.

[15] Martin LF, Kem WR, Freedman R. $\alpha 7$ nicotinic receptor agonists: Potential new candidates for the treatment of schizophrenia. Psychopharmacology 2004; 174: 54-6.

[16] Leonard S, Breese C, Adams C, et al. Smoking and schizophrenia: Abnormal nicotinic receptor expression. Eur J Pharmacol 2000; 393: $237-42$.

[17] Glassman AH. Cigarette smoking: implications for psychiatric illness. Am J Psychiatry 1993; 150: 546-53.

[18] Ziedonis DM, George TP. Schizophrenia and nicotine use: a report of a pilot smoking cessation program and a review of neurobiological and clinical issues. Schizophr Bull 1997; 23: 247-54.

[19] Breese CR, Lee MJ, Adams CE, et al. Abnormal regulation of high-affinity nicotinic receptors in subjects with schizophrenia. Neuropsychopharmacology 2000; 23: 351-64.

[20] Besson M, Granon S, Mameli-Engvall M, et al. Long-term effects of chronic nicotine exposure on brain nicotinic receptors. Proc Natl Acad Sci USA 2007; 104: 8155-60.

[21] Powchik P, Davidson M, Haroutunian V, et al. Postmortem studies in schizophrenia. Schizophr Bull 1998; 24: 325-41.

[22] Walters CL, Brown S, Changeux JP, Martin B, Damaj MI. The $\beta 2$ but not $\alpha 7$ subunit of the nicotinic acetylcholine receptor is required for nicotine-conditioned place preference in mice. Psychopharmacology 2006; 184: 339-44.

[23] Mizoguchi H, Arai S, Koike H, et al. Therapeutic potential of nicotine for methamphetamine-induced impairment of sensorimotor gating: involvement of pallidotegmental neurons. Psychopharmacology 2009; 207: 235-43.

[24] Lee PR, Brady DL, Shapiro RA, Dorsa DM, Koenig JI. Social interaction deficits caused by chronic phencyclidine administration are reversed by oxytocin. Neuropsychopharmacol 2005; 30: 188394.

[25] Wang D, Noda Y, Tsunekawa H, et al. Role of N-methyl-Daspartate receptors in antidepressant-like effects of sigma 1 receptor agonist 1-(3,4-Dimethoxyphenethyl)-4-(3-phenylpropyl) piperazine dihydrochloride (SA-4503) in olfactory bulbectomized rats. J Pharmacol Exp Ther 2007; 322: 1305-14.

[26] Tremolizzo L, Doueiri MS, Dong E, et al. Valproate corrects the schizophrenia-like epigenetic behavioral modifications induced by methionine in mice. Biol. Psychiatry 2005; 57: 500-9.

[27] Nagai T, Takuma K, Kamei H, et al. Dopamine D1 receptors regulate protein synthesis-dependent long-term recognition memory via extracellular signal-regulated kinase $1 / 2$ in the prefrontal cortex. Learn Mem 2007; 14: 117-25.

[28] Takahashi K, Nagai T, Kamei H, et al. Neural circuits containing pallidotegmental GABAergic neurons are involved in the prepulse inhibition of the startle reflex in mice. Biol Psychiatry 2007; 62: 148-57.

[29] Arai S, Takuma K, Mizoguchi $\mathrm{H}$, et al. Involvement of pallidotegmental neurons in methamphetamine- and MK-801induced impairment of prepulse inhibition of the acoustic startle reflex in mice: reversal by GABAB receptor agonist Baclofen. Neuropsychopharmcology 2008; 33: 3164-75.

[30] Clancy B, Darlington RB, Finlay BL. Translating developmental time across mammalian species. Neuroscience 2001; 105: 7-17.

[31] Bayer SA, Altman J, Russo RJ, Zhang X. Timetables of neurogenesis in the human brain based on experimentally determined patterns in the rat. Neurotoxicology 1993; 14: 83-144.

[32] Adler LE, Hoffer LD, Wiser A, Freedman R. Normalization of auditory physiology by cigarette smoking in schizophrenic patients. Am J Psychiatry 1993; 150: 1856-61. 
[33] Luntz-Leybman V, Bickford PC, Freedman R. Cholinergic gating of response to auditory stimuli in rat hippocampus. Brain Res 1992; 587: $130-6$.

[34] Simosky JK, Stevens KE, Kem WR, Freedman R. Intragastric DMXB-A, an alpha7 nicotinic agonist, improves deficient sensory inhibition in DBA/2 mice. Biol Psychiatry 2001; 50: 493-500.

[35] Geyer MA, Krebs-Thomson K, Braff DL, Swerdlow NR. Pharmacological studies of prepulse inhibition models of sensorimotor gating deficits in schizophrenia: a decade in review. Psychopharmacology 2001; 156: 117-54.

[36] Mansvelder HD, McGehee DS. Cellular and synaptic mechanisms of nicotine addiction. J Neurobiol 2002; 53: 606-17.

[37] Corringer PJ, Le Novere N, Changeux JP. Nicotinic receptors at the amino acid level. Annu Rev Pharmacol Toxicol 2000; 40: 431-58.

[38] McGehee DS, Role LW. Physiological diversity of nicotinic acetylcholine receptors expressed by vertebrate neurons. Annu Rev Physiol 1995; 57: 521-46.

[39] Broide RS, O'Connor LT, Smith MA, et al. Developmental expression of $\alpha 7$ neuronal nicotinic receptor messenger RNA in rat sensory cortex and thalamus. Neuroscience 1995; 67: 83-94.

[40] Zhang X, Liu C, Miao H, et al. Postnatal changes of nicotinic acetylcholine receptor $\alpha 2, \alpha 3, \alpha 4, \alpha 7$ and $\beta 2$ subunits genes expression in rat brain. Int J Dev Neurosci 1998; 16: 507-18.

[41] Freedman R, Hall M, Adler LE, Leonard S. Evidence in postmortem brain tissue for decreased numbers of hippocampal nicotinic receptors in schizophrenia. Biol Psychiatry 1995; 38: 2233 .
[42] Freedman R, Coon H, Myles-Worsley M, et al. Linkage of a neurophysiological deficit in schizophrenia to a chromosome 15 locus. Proc Natl Acad Sci USA 1997; 94: 587-92.

[43] Riley BP, Makoff A, Mogudi-Carter M, et al. Haplotype transmission disequilibrium and evidence for linkage of the CHRNA7 gene region to schizophrenia in Southern African Bantu families. Am J Med Genet 2000; 96: 196-201.

[44] Bontempi B, Whelan KT, Risbrough VB, et al. SIB-1553A, (+/-)4-[[2-(1-methyl-2-pyrrolidinyl)ethyl]thio]phenol hydrochloride, a subtype-selective ligand for nicotinic acetylcholine receptors with putative cognitive-enhancing properties: effects on working and reference memory performances in aged rodents and nonhuman primates. J Pharmacol Exp Ther 2001; 299: 297-306.

[45] Mitchell SN. Role of the locus coeruleus in the noradrenergic response to a systemic administration of nicotine. Neuropharmacology 1993; 32: 937-49.

[46] Ribeiro EB, Bettiker RL, Bogdanov M,Wurtman RJ. Effects of systemic nicotine on serotonin release in rat brain. Brain Res 1993; 621: 311-8.

[47] Kenny PJ, File SE, Neal MJ. Evidence for a complex influence of nicotinic acetylcholine receptors on hippocampal serotonin release. J Neurochem 2000; 75: 2409-14.

[48] Ge S, Dani JA. Nicotinic acetylcholine receptors at glutamate synapses facilitate long-term depression or potentiation. J Neurosci 2005; 25: 6084-91.

[49] Konradsson-Geuken A, Gash CR, Alexander K, et al. Second-bysecond analysis of $\alpha 7$ nicotine receptor regulation of glutamate release in the prefrontal cortex of awake rats. Synapse 2009; 63: 1069-82

\author{
Received: December 18, 2009 \\ Revised: March 08, 2010 \\ (C) Yu et al.; Licensee Bentham Open.
}

Accepted: July 05, 2010

This is an open access article licensed under the terms of the Creative Commons Attribution Non-Commercial License (http://creativecommons.org/licenses/bync/3.0/), which permits unrestricted, non-commercial use, distribution and reproduction in any medium, provided the work is properly cited 